BY NC ND

Estudos Teológicos foi licenciado com uma Licença Creative Commons Atribuição - NãoComercial - SemDerivados 3.0 Não Adaptada

http://dx.doi.org/10.22351/et.v57i1.2803

\title{
A realidade do ensino religioso no estado do Amapá: PROPOSTA DE CRIAÇÃO DO PRIMEIRO CURSO DE LICENCIATURA EM CIÊNCIA DA RELIGIÃ̃ ${ }^{1}$
}

\author{
The reality of Religious Education in Amapá State: \\ a proposal of establishing the first licentiate course in Religious Studies
}

\section{Elivaldo Serrão Custódio ${ }^{2}$ Marcos Vinicius de Freitas Reis ${ }^{3}$ Oneide Bobsin ${ }^{4}$}

Resumo: O presente trabalho tem por objetivo trazer reflexões sobre a realidade do Ensino Religioso no estado do Amapá, bem como a proposta de criação do primeiro curso de licenciatura em Ciência da Religião no estado. Trata-se do resultado de um estudo exploratório, de natureza qualitativa, que adotou a pesquisa bibliográfica e a análise documental como forma de investigação. No primeiro momento, abordamos os desafios e as dificuldades da formação de professores/as de Ensino Religioso no estado. Em seguida, apresentamos uma análise sucinta da proposta de criação do curso de licenciatura em Ciência da Religião pela Universidade Federal do Amapá (UNIFAP), levando em consideração o

1 O artigo foi recebido em 26 de julho de 2016 e aprovado em 14 de abril de 2017 com base nas avaliações dos pareceristas ad hoc.

2 Doutorando em Teologia pela Escola Superior de Teologia (Faculdades EST) em São Leopoldo/RS, Brasil. Bolsista da CAPES. Mestre em Direito Ambiental e Políticas Públicas pela Universidade Federal do Amapá (UNIFAP). Docente da Secretaria de Estado de Educação do Amapá (SEED). Editor associado da revista Identidade, da Faculdades EST. Membro pesquisador do Grupo de Pesquisa Centro de Estudos Políticos, Religião e Sociedade (CEPRES-UNIFAP/CNPq), do Grupo de Pesquisa Educação, Relações Étnico-Raciais e Interculturais (UNIFAP/CNPq), do Grupo de Pesquisa Currículo, Identidade Religiosa e Práxis Educativa e do Grupo de Pesquisa Identidade (Faculdades EST/CNPq). Contato: elivaldo.pa@ hotmail.com

3 Professor da Universidade Federal do Amapá (UNIFAP), em Macapá, Brasil, do curso de graduação em Relações Internacionais. Doutor em Sociologia pela Universidade Federal de São Carlos (UFSCAR). Membro do Núcleo de Estudos de Religião, Economia e Política (NEREP-UFSCAR/CNPq). Pesquisador do Observatório em Direitos Humanos da Amazônia (OBADH-UNIFAP/CNPq), Líder do Centro de Estudos Políticos, Religião e Sociedade (CEPRES-UNIFAP/CNPq). Contato: marcosvinicius5@yahoo.com.br

4 Professor titular de Ciências da Religião dos cursos de graduação, mestrado e doutorado em Teologia da Faculdades EST, em São Leopoldo/RS, Brasil. Doutor em Ciências Sociais pela Pontifícia Universidade Católica de São Paulo (PUC-SP). Líder do Grupo de Pesquisa Identidade. Coordenador do Núcleo de Estudo e Pesquisa do Protestantismo (NEPP) e editor de Protestantismo em Revista, da Faculdades EST. Contato: obobsin@est.edu.br 
histórico da proposta, seus objetivos, concepção epistemológica, dificuldades encontradas e a importância desse curso para a sociedade amapaense.

Palavras-chaves: Ciência da Religião. Ensino Religioso. Religião e Educação. Amapá.

Abstract: This work aims to bring reflections on the reality of Religious Education in the state of Amapá and the proposal of creating the first Bachelor of Religious Studies in the state. This is the result of an exploratory study, of qualitative nature, which adopted the literature search and document analysis as a form of research. At first, we discuss the challenges and difficulties of teachers of religious education in the state. Next, we present a brief analysis of proposal for creating a Bachelor of Religious Studies at the Federal University of Amapá (UNIFAP), taking into consideration the history of the proposal, its objectives, epistemological conception, difficulties, and the importance of this course to the Amapá society.

Keywords: Religious Studies. Religious Education. Religion and Education. Amapá.

\section{Considerações iniciais}

Percebemos uma imensa diversidade religiosa no estado do Amapá. Andando pelas ruas dos centros urbanos dos municípios amapaenses, deparamo-nos com templos evangélicos, igrejas católicas, centros esotéricos, instituições espíritas e organizações de religiões de matriz africana, repletos de pessoas que buscam respostas para suas necessidades cotidianas. ${ }^{5}$

Os veículos de comunicação da sociedade amapaense tornaram-se alvos prediletos das lideranças religiosas. Não são raras as vezes em que, vendo um canal de televisão, abrindo um jornal, navegando na internet ou sintonizando uma determinada emissora de rádio, encontramos uma exaustiva e extensa programação religiosa com o objetivo de angariar mais fiéis. Com promessas de curas, milagres, ensinos doutrinários, libertações e, sobretudo, ascensão financeira e social, as programações religiosas, principalmente as pentecostais, ocupam horários até então impensáveis para o telespectador. ${ }^{6}$

No campo caritativo, existem iniciativas filantrópicas que, em nome de um ethos religioso, praticam obras sociais. Podemos citar, como exemplo, o trabalho com dependentes químicos e/ou na recuperação de alcoólatras, a ajuda financeira a men-

5 De acordo com os dados do IBGE de 2010 sobre o panorama religioso da população do estado do Amapá, $63,5 \%$ se identificam com o catolicismo; $28 \%$ evangélicos; 5,5\% sem religião; 0,4\% espíritas; $0,1 \%$ religiões afro-brasileiras e 2,3\% outras religiões. Percebemos que existe um pluralismo cristão na sociedade amapaense (SOUZA, André Ricardo. Pluralismo Cristão Brasileiro. Caminhos, Goiânia, v. 10, n. 1, p. 129-141, jan./jun. 2012. Disponível em: <http://seer.ucg.br/index.php/caminhos/article/view/1953/1218>. Acesso em: 05 jan. 2016.).

6 REIS, Marcos Vinicius de Freitas; CARMO, Arielson Teixeira do. O campo religioso amapaense: Uma análise a partir do Censo do IBGE de 2000 e 2010. Observatório da Religião, Belém-PA, v. 2, n. 02, p. 175-197, jun./dez. 2015. Disponível em: <http://paginas.uepa.br/seer/index.php/Religiao/article/ view/834/595>. Acesso em: 04 jun. 2016. 
digos, famílias carentes e instituições sociais, os trabalhos voluntários desenvolvidos em hospitais, presídios, creches e escolas, dentre outros. ${ }^{7}$

$\mathrm{O}$ mercado editorial tem-se surpreendido com o elevado número de vendagens de livros que fornecem conselhos e conforto espiritual para os problemas da humanidade, a exemplo de produções no campo da autoajuda ou, até mesmo, em publicações católicas (livros do Padre Jonas) e evangélicas (Edir Macedo). No campo fonográfico, grupos gospel e padres cantores fazem apresentações musicais em eventos religiosos no Amapá arrebanhando milhares de fãs, dentre eles, estão: padre Marcelo Rossi, padre Fábio de Mello, Diante do Trono, Aline Barros, Oficina G3 e Toque no Altar, entre outros/as. ${ }^{8}$

Enfim, o estado do Amapá parece nunca ter presenciado tamanha oferta de práticas religiosas no cotidiano das pessoas, e isso tem despertado cada vez mais interesse de pesquisadores/as e das diversas áreas das ciências humanas a se debruçarem sobre a temática, para entender como o fenômeno religioso tem afetado a organização das instituições sociais e a vida das pessoas.

Nas escolas, também percebemos a pluralidade religiosa, pois alunos/as, professores/as, diretores/as, secretários/as e demais funcionários/as são vinculados/as às mais diferentes confissões religiosas, por isso são comuns a execução de canções religiosas nos intervalos, o uso de vestimentas que os identificam com alguma instituição religiosa, além de situações de intolerância religiosa vivenciadas no cotidiano dos estabelecimentos de ensino no estado do Amapá. Perante essa realidade, o sistema educacional religioso precisa lidar com esse contexto pluralista, pois a formação docente e a metodologia abordada em sala precisam promover a tolerância entre os/as alunos/as e evitar qualquer manifestação proselitista. ${ }^{9}$

Nesse intuito, a Universidade Federal do Amapá (UNIFAP) propõe a criação do Curso de Licenciatura em Ciência da Religião e, em parceria com a Secretaria de Educação do Estado do Amapá (SEED), discutir a elaboração de projetos que contribuam para uma boa formação de docentes de Ensino Religioso.

Assim, este trabalho tem por objetivo trazer uma reflexão sobre a realidade do Ensino Religioso no estado do Amapá. Trata-se do resultado de um estudo exploratório, de natureza qualitativa, que adotou a pesquisa bibliográfica e a análise documental como forma de investigação. Na primeira parte deste trabalho serão abordados os desafios da formação de professores/as de Ensino Religioso no estado. Em seguida, será apresentada uma análise da proposta da criação do Curso de Licenciatura em Ciência

\footnotetext{
REIS; CARMO, 2015.

REIS; CARMO, 2015.

9 Sobre a pluralidade religiosa nas escolas públicas no estado do Amapá, as pesquisas de Custódio (2012, $2013,2014,2015,2016$ ) apontam que embora exista todo um marco legal que garante a liberdade e a pluralidade religiosa no espaço escolar, têm-se percebido, na educação pública amapaense, muitos profissionais sem qualificação específica, habilidade e/ou vontade em reconhecer e respeitar as diferenças ou crenças religiosas, em especial no currículo do componente Ensino Religioso. Acreditamos que a intolerância religiosa não deve se fazer presente nas escolas nem em qualquer outro espaço social, pois é uma prática discriminatória e exclusiva. Assim é importante promover, no espaço escolar, discussões que contextualizem o exercício de cidadania e o diálogo com o diferente.
} 
da Religião pela UNIFAP, levando em consideração o histórico da proposta, seus objetivos, concepção epistemológica, suas dificuldades e a importância desse curso para a sociedade amapaense.

\section{Formação de professores/as de Ensino Religioso no Amapá: desafios e perspectivas}

A questão do Ensino Religioso está relacionada à evolução histórica da educação e à legislação normativa sobre a formação docente. O presente tópico discute e analisa a experiência de formação de professores/as de Ensino Religioso no estado do Amapá. Não se discute se esse ensino deve ou não estar na escola pública, embora a questão seja subjacente. Partimos do ponto que está definido na legislação e, portanto, pressupõe professores/as habilitados/as para isso.

Refletir sobre a formação de professores/as e de profissionais da educação na atual sociedade é da maior importância e urgência. $\mathrm{O}$ enfrentamento dos problemas existentes na sua formação, na qual a articulação entre a técnica, o conhecimento e a análise crítica precisam ser elementos presentes e imbricados, com vistas a preparar professores/as que sejam formadores/as de cidadãos, considerados pessoas autônomas, capazes de selecionar, identificar e analisar informações, em interação social, a fim de construir um juízo crítico. ${ }^{10}$

Para a legislação vigente, o Ensino Religioso compõe a grade curricular da escola e requer professores/as habilitados/as e competentes. Essas condições impõem novas exigências a esse ensino no currículo escolar e ampliam-se os requisitos do profissional que poderá atuar nessa área do conhecimento. Somos conhecedores/as que, na história da educação brasileira, a formação desse profissional foi marcada por avanços e retrocessos que nem sempre corresponderam aos anseios da sociedade. Antônio Nóvoa já enfatizava que "não há ensino de qualidade, nem reforma educativa, nem inovação pedagógica, sem uma adequada formação de professores"11.

O Ensino Religioso e a formação de professores/as significam a possibilidade de uma nova forma de se educar para a diversidade cultural religiosa da humanidade, assim como o auxílio na promoção da dignidade, do respeito e da liberdade individual, em clima de diálogo. Cada vez mais investigadores/as e pesquisadores/as passam a se dedicar ao estudo do Ensino Religioso e a colaborar na construção de uma epistemologia própria à disciplina que, a partir de 1997, passou à responsabilidade do estado e não mais de religiões, igrejas ou grupos religiosos.

Segundo Lurdes Caron, a Constituição Federal de 1988 e a Lei de Diretrizes e Bases da Educação Nacional (LDBEN) de 1996 normatizam o Ensino Religioso no sistema nacional de ensino. A despeito da polêmica em torno da questão, o Estado

\footnotetext{
${ }^{10}$ CUSTÓDIO, Elivaldo Serrão. Politicas públicas e direito ambiental cultural: as religiões de matrizes africanas no currículo escolar no Amapá. 2014. 198f. Dissertação (Mestrado em Direito Ambiental e Políticas Públicas) - Universidade Federal do Amapá, Macapá, 2014. p. 420.

11 NÓVOA, Antônio. Os professores e a sua formação. Lisboa: Dom Quixote, 1992. p. 9.
} 
deve estabelecer, segundo as normas constitucionais, a política de Ensino Religioso e, portanto, a política de formação de profissionais para essa disciplina escolar. ${ }^{12}$

O Estado, ao legislar sobre esse componente curricular, delega aos sistemas estaduais e municipais a incumbência de introduzir o Ensino Religioso no ensino regular, ordenando a atividade dos docentes em caráter temporário ${ }^{13}$ ou via concurso ${ }^{14}$ de acesso ao quadro regular de magistério público. $\mathrm{Na}$ atual conjuntura, a União e os estados deixaram a formação de professores/as, bem como o conteúdo do Ensino Religioso, por vezes, ao encargo de entidades religiosas, civis e/ou educacionais.

É urgente repensar políticas para a formação de professores/as, pois a transformação da escola frente às exigências impostas pela globalização, pela reestruturação produtiva, pelas políticas educacionais e sociedade depende em grande parte da habilitação, qualificação e competência dos/as professores/as.

O atual momento histórico da educação brasileira, marcado por inquietações, indagações e indefinições políticas desafia a educação que privilegie o ser humano de forma plena. Para tanto precisa-se de uma efetiva qualificação de professores/as, pois as mudanças curriculares exigem habilitação e competência dos profissionais da educação. E essa formação processa-se em articulação com a reflexão sobre as práticas.

A formação não se constrói por acumulação (de cursos, de conhecimentos ou técnicas), mas sim através de um trabalho de reflexibilidade crítica sobre as práticas e de (re) construção permanente de uma identidade pessoal. Por isso é tão importante investir na pessoa e dar um estatuto ao saber da experiência. ${ }^{15}$

Nos últimos vinte anos, no meio universitário e nas associações de docentes, a discussão a respeito da melhoria da formação de professores/as de todos os níveis de ensino vem sendo ampliada, pois está relacionada aos contextos sociopolítico, econômico e cultural da sociedade contemporânea. Assim, pensar na profissionalização do/a professor/a é pensar na especificidade que a profissão envolve, a considerar que o/a professor/a precisa adquirir seus conhecimentos, colocando-os em prática, isto é, ser capaz de refletir e avaliar sua própria ação, ser crítico, pragmático, ser responsável e participativo, ao mesmo tempo ser autônomo em suas ações, saber trabalhar e produzir coletivamente.

${ }^{12}$ CARON, Lurdes. Politicas e Práticas Curriculares: Formação de professores de Ensino Religioso. Tese (Doutorado em Educação: currículo) - Pontifícia Universidade Católica de São Paulo - PUC-SP, São Paulo, 2007. 354p. Disponível em: <http://www.sapientia.pucsp.br/tde_arquivos/11/TDE-2008-0103T06:54:24Z-4689/Publico/Lurdes\%20Caron\%20desp\%20(sem\%20o\%20anexo\%203).pdf>. Acesso em: 08 jun. 2014.

${ }^{13}$ Entende-se por Admitidos/as em Caráter Temporário (ACT), a admissão de professores/as realizada pelo estado, normalmente no início do ano, encerrando-se no final do ano em exercício. Enquanto não tiver o/a professor/a habilitado/a na área, o/a docente pode-se inscrever para ser admitido como ACT. Essa situação é para todos os componentes do currículo escolar.

${ }^{14} \mathrm{O}$ estado e/ou município, segundo a legislação pertinente, possibilita a docentes de Ensino Religioso, por meio de concurso, ter acesso ao Quadro do Magistério Público.

${ }_{15}$ NÓVOA, 1992, p. 25. 
Para Lurdes Caron ${ }^{16}$ e Sérgio Rogério Azevedo Junqueira ${ }^{17}$, a formação de docentes $^{18}$ para o Ensino Religioso no Brasil, até a década de 1990, era orientada pelas denominações religiosas cristãs. Existem experiências sobre essa formação ser desenvolvida em parceria e/ou articulação entre denominações religiosas, sistemas de ensino e instituições de ensino superior (IES).

A partir de 1997, o Ensino Religioso brasileiro passou por mudança de paradigma, com a Lei $n^{\circ} 9.475$, de 22 de julho de 1997, que deu nova redação ao artigo 33 da Lei no 9.394, de 20 de dezembro de 1996, que estabeleceu as Diretrizes e Bases da Educação Nacional. Por essa lei é atribuída aos sistemas de ensino a admissão, a habilitação e a capacitação do/a docente de Ensino Religioso. A partir de então a formação de professores/as para o Ensino Religioso configura-se nos mais distintos segmentos do ensino superior: graduação, pós-graduação - especialização; programas de mestrado e doutorados - livres. ${ }^{19}$

Entre os principais responsáveis pela atualização desses/as professores/as estão os sistemas de ensino municipal e estadual, por meio de encontros, cursos e outros eventos realizados em diferentes regiões, de forma presencial e/ou a distância. No entanto, existem estados que ainda não encontraram um caminho que permita chegar aos trâmites normais para estabelecer políticas de formação, que, por meio de cursos de licenciatura plena, ofereçam a habilitação para o/a professor/a em Ensino Religioso e a consequente efetivação desse profissional no quadro do magistério público, na área de sua atuação.

Com relação à legislação, é crescente o número de secretarias estaduais e municipais que estão organizando o Ensino Religioso quanto à estrutura, concepção, formação e admissão de professores/as, mediante leis, decretos, resoluções, pareceres e portarias. Em se tratando especificamente do estado do Amapá, segundo nossas pesquisas, de acordo com os dados no sítio do Ministério da Educação (MEC) até o ano de 2011, não havia cursos de licenciatura cadastrados para formar o/a professor/a do Ensino Religioso no Amapá. Existiam apenas cursos de bacharéis, cursos livres, de extensão ou de especialização para complementar a formação de professores/as de outras áreas no campo do Ensino Religioso. E, em consequência disso, o processo de formação do/a professor/a de Ensino Religioso no estado do Amapá era deficitário. ${ }^{20}$

${ }^{16}$ CARON, Lurdes. Entre Conquistas e Concessões: uma experiência ecumênica em educação religiosa escolar. São Leopoldo: Sinodal, 1997.

17 JUNQUEIRA, Sérgio Rogério Azevedo. O processo de escolarização do Ensino religioso no Brasil. Petrópolis: Vozes, 2002.

18 Ver pesquisas de CARON, Lurdes. Políticas públicas para a formação de professores para a educação básica. In: JUNQUEIRA, Sérgio Rogério Azevedo; OLIVEIRA, Lílian Blanck (Orgs.). Ensino Religioso: memórias e perspectivas. Curitiba: Champagnat, 2005. p. 99-117; CARON, Lurdes. Experiências e propostas de educação continuada. I Fórum de Ensino Religioso. Secretaria de Educação e Cultura e Faculdade Católica de Tocantins, 2005. p. 19-20.

19 Ver pesquisa de JUNQUEIRA, Sergio et al. Formação do professor de ensino religioso: uma realidade desafiadora no Brasil. 2006. Disponível em: $<$ http://www.pucpr.br/eventos/educere/educere2006/anaisEvento/docs/CI-041-TC.pdf>. Acesso em: 10 jun. 2014

${ }^{20}$ CUSTÓDIO, Elivaldo Serrão. Formação de professores de ensino religioso no Amapá. In: SEMINÁRIO NACIONAL DE FORMAÇÃO DE PROFESSORES PARA O ENSINO RELIGIOSO, 12., 2012, Manaus. 
Em recente pesquisa no portal do MEC, em julho de 2016, constatamos que até o presente momento também não há avanços de cadastramento e/ou reconhecimento de cursos de licenciatura em Ensino Religioso no estado do Amapá. De acordo com nossa pesquisa, a maioria dos/as professores/as efetivos/as e/ou contratados/as pela $\mathrm{SEED} / \mathrm{AP}$ não possui formação específica para atuar no componente Ensino Religioso Escolar ( $6^{\circ}$ ao $9^{\circ}$ ano do ensino fundamental), sendo muitos/as desses/as profissionais das áreas de Teologia, Pedagogia, História, Sociologia e/ou Filosofia.

Em trecho de entrevista com a representante da Unidade de Cadastro (UCAD) da SEED/AP, Elivaldo Serrão Custódio destaca que: "antigamente como o estado não oferecia essa qualificação específica, os servidores eram lotados nas disciplinas que tinham afinidade". Essa afirmação demonstra, no mínimo, um descaso com a educação pública, pois percebemos que as autoridades governamentais no Amapá não observam o que rege a lei maior (Lei n ${ }^{\circ}$ 9.475/1997, que deu nova redação ao Art. 33 da Lei $n^{0}$ 9.394/1996). ${ }^{21}$

A presença do Ensino Religioso nas escolas da rede pública está envolta em um amplo conjunto de polêmicas por parte de pessoas que desconhecem a verdadeira identidade tanto dessa disciplina quanto do papel de seus/suas professores/as. Mesmo assim, a disponibilização dela na grade curricular é garantida por lei, pois a liberdade de pensamento é uma garantia constitucional. ${ }^{22}$

Nesse sentido, o estado do Amapá, no ano de 2006, promulgou a Resolução n ${ }^{\circ}$ 14/2006-CEE/AP ${ }^{23}$, para normatizar esse ensino no estado. De acordo com o artigo 4 da Resolução n 14/2006-CEE/AP, fica estabelecido que:

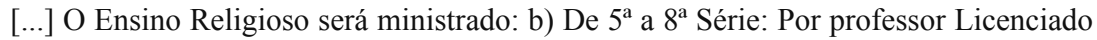
Pleno ou Especialista em Ensino Religioso/Ciência da Religião/Educação Religiosa. § $1^{\circ}$. Compete à Secretaria Estadual de Educação, para os fins dispostos nesta Resolução, planejar, executar, acompanhar e avaliar o processo de capacitação e habilitação do professor de Ensino Religioso nas escolas públicas do ensino fundamental integrantes do Sistema Estadual de Ensino. [...] § $3^{\circ}$. A Secretaria Estadual de Educação promoverá no prazo máximo de 06 (seis) anos a habilitação dos professores que atuam no Ensino Religioso sem a formação adequada, como forma de valorização da docência no Ensino Religioso $[\ldots]^{24}$.

A LDBEN estabelece que a habilitação dos/as professores/as seja de competência dos estados da federação. Mas a oferta de cursos para a formação de professor/a de Ensino Religioso ainda não atende à crescente demanda. Em alguns estados, como

Anais... Florianópolis: Fonaper, 2012, p. 424. Disponível em: <www.gper.com.br/biblioteca_download. php?arquivoId=880>. Acesso em: 20 jul. 2014.

21 CUSTÓDIO, 2012, p. 425.

22 CUSTÓDIO, 2012, p. 425.

23 A Resolução de n ${ }^{\circ} 14$ de 15/03/2006 foi assinada pelo professor Paulo Fernando Batista Guerra. Na época, presidente do Conselho Estadual de Educação do Amapá (CEE-AP), Decreto n 2523/2004.

${ }^{24}$ BRASIL. Resolução no 14/2006. Conselho Estadual de Educação/AP. Macapá, 12 de fevereiro de 2006. Disponível em:<www.gper.com.br/biblioteca_download.php?arquivoId=136>. Acesso em: 20 jul. 2014. 
no Amapá, mesmo com a realização de concurso público, monitores/as e/ou licenciados/as em outras áreas são contratados/as para suprir carências.

A SEED/AP, até a presente data, vem apresentando dificuldade em seu quadro docente para o Ensino Religioso, principalmente para os anos finais do ensino fundamental. Em nossas pesquisas, observamos que, nos últimos anos, nessa área específica de conhecimento, o governo do Amapá não tem observado as diretrizes legais que regem o magistério para os anos finais desse nível de ensino em que está prevista a formação de docente habilitado em curso de licenciatura plena, reafirmado no artigo 4 da Resolução no 14/2006-CEE/AP.

Vale ressaltar que o governo do estado do Amapá, até o presente momento, não adotou nenhuma política pública de formação inicial ou continuada para professores/ as de Ensino Religioso. Segundo ainda nossa pesquisa de mestrado, o governo do estado do Amapá, por meio da SEED/AP, não implementou políticas públicas de formação e/ou capacitação de professores/as de Ensino Religioso desde a promulgação da Resolução no 14/2006-CEE/AP, de acordo com a entrevista da representante da Associação de Professores/as de Ensino Religioso do Amapá (APERAP). ${ }^{25}$

Segundo a representante da APERAP, sempre havia encontros, às segundas-feiras, na Arquidiocese da Igreja Católica de Macapá para os/as professores/as de Ensino Religioso para partilhar experiência e material, elaborar plano de aula, novas metodologias e estratégias. Em uma única reunião, chegavam a reunir até cem (100) professores, mas infelizmente essas reuniões deixaram de acontecer desde o ano de $2010 .^{26}$

Observamos ainda que, mesmo diante dessas dificuldades e/ou descaso por parte do poder público em relação à formação de professores/as nessa área do conhecimento, encontramos algumas iniciativas de instituições privadas que demonstraram interesse em suprir essa deficiência no estado, como a Faculdade de Teologia e Ciências Humanas (FATECH) - na cidade de Macapá/AP, credenciada e reconhecida pelo MEC, a qual possui um Curso de Especialização em Ensino Religioso (360h), presencial desde março de 2011, e o Instituto Brasileiro de Pós-Graduação e Extensão (IBPEX), que oferece Especialização em Metodologia do Ensino Religioso (360h) desde 2009, na modalidade semipresencial e a distância, entre outras instituições de ensino superior que oferecem formação específica na modalidade a distância.

Os cursos oferecem ferramentas metodológicas, pesquisas e capacitação para a formação de professores/as do Ensino Religioso de escolas municipais, estaduais ou particulares. Merece destaque, também, a Faculdade SEAMA, em Macapá/AP, que em 2006 ofertou, na modalidade presencial, o curso de Especialização em Ensino Religioso (360h), porém, após um ano de existência, o curso deixou de ser oferecido devido ao baixo índice de procura.

Ressaltamos que a FATECH, nos últimos anos, vem se destacando no campo educacional amapaense no que tange ao oferecimento de cursos de especialização na

${ }^{25}$ CUSTÓDIO, 2014, p. 131.
${ }^{26}$ CUSTÓDIO, 2014, p. 131. 
área do Ensino Religioso. Essa instituição, no período de 2011 a 2015, já capacitou 15 turmas de Especialização em Ensino Religioso, qualificando mais de 290 profissionais, e desses, mais de 120 são professores/as da rede pública estadual do Amapá. Segundo ainda informações dessa instituição, o Programa de Pós-Graduação em Ensino Religioso parte do princípio de que a educação tem como objetivo final o desenvolvimento pleno do sujeito humano na sociedade. Nesse sentido, o Ensino Religioso é concebido como uma disciplina que contribui para a formação do ser humano e, sobretudo, para o seu estado de realização integral. Sua proposta é a de repensar o conceito de Ensino Religioso, sua prática pedagógica, sua definição de conteúdos, sua natureza e metodologia, para adequar o ensino ao universo escolar, como propõem os Parâmetros Curriculares Nacionais (PCNs), e de forma a despertar nas futuras gerações uma visão crítica sobre o fenômeno religioso. ${ }^{27}$

Enfim, o que entendemos em torno dessa discussão é que precisamos repensar a formação de professores/as de Ensino Religioso no Amapá, pois não podemos considerar essa formação dissociada da reflexão crítica acerca de nossa realidade. É preciso refletir sobre essa dimensão por meio de políticas públicas eficazes, bem como de propostas curriculares, de atividades que permitam uma formação inicial e continuada de boa qualidade e que atenda nossas necessidades.

\section{Proposta para a criação da graduação em Ciência da Religião no Amapá}

No dia 13 de março de 2014, o então reitor da Universidade Federal do Amapá assinou a Portaria n ${ }^{\circ}$ 363/2014 que permitiu o início dos trabalhos da Comissão de Elaboração do Projeto Político Pedagógico do Curso de Licenciatura em Ciência da Religião.

A maioria dos/as docentes que compõem a comissão é vinculada ao grupo de pesquisa Centro de Estudos Políticos, Religião e Sociedade (CEPRES/UNIFAP). Os docentes são: Dr. Andrius Estevam Noronha, Dr. José Carlos Cariacas Romão da Silva, Dr. Aldenor Benjamim, Dr. Marcos Vinicius de Freitas Reis, Msc. Antônio de Almeida da Silva, Msc. Elivaldo Serrão Custódio, Msc. Renan Marques Birro, Prof. Msc. Fábio Py Murta de Almeida, Prof ${ }^{a}$. Esp. Lourdes Vulcão, Prof. Esp. Emanuel Leal Lima, entre outros/as.

A proposta do curso de graduação apresenta as seguintes proposições: (a) o aluno formado terá a habilitação Licenciado em Ciência da Religião; (b) a forma de ingresso será pelo Sistema de Seleção Unificada - SISU; (c) a modalidade de ensino será presencial; (d) o regime de matrícula por meio de crédito semestral. Anualmente, o curso ofertaria quarenta (40) vagas e as aulas aconteceriam no período noturno. $\mathrm{O}$ turno de funcionamento da secretaria estaria estabelecido no período vespertino e

\footnotetext{
27 Informações e dados concedidos pela secretaria administrativa da FATECH em 25 de agosto de 2015. Para maiores informações, ver site oficial da instituição em: <http://faculdadefatech.com.br>.
} 
noturno e os discentes teriam, no mínimo, oito (8) semestres e, no máximo, doze (12) semestres para integralização das disciplinas.

Aprovado, o curso funcionará no campus Marco Zero, situado na cidade de Macapá, estado do Amapá, no endereço Rod. Juscelino Kubitschek, KM-02 Jardim Marco Zero Macapá/AP, CEP 68.903-419, cujo primeiro coordenador seria o Prof. Dr. Marcos Vinicius de Freitas Reis, com a ajuda de um servidor público no tocante aos serviços de administração e secretaria, além do Núcleo Docente Estruturante (NDE) composto pelos Prof. Msc. Antônio de Almeida Rodrigues da Silva, Prof. Dr. Andrius Estevam Noronha, Prof. Dr. José Carlos Cariacas Romão da Silva, Prof. Msc. Renan Marques Birro, e outros/as docentes integrados/as, que seriam contratados/as por concurso público para cargo efetivo com dedicação exclusiva de 40 horas.

A ideia da criação do Curso de Licenciatura em Ciência da Religião deu-se em conversa com membros da APERAP. Frequentando algumas assembleias da instituição, sempre alegavam que a SEED não investia pesadamente na formação continuada de professores/as de Ensino Religioso e não se preocupava com a formação de novos/as docentes capacitados/as para tal habilitação profissional, ou seja, o estado do Amapá carece de uma instituição que ofereça formação contínua para profissionais que desejam trabalhar com o Ensino Religioso no ensino público e privado. Logo, a UNIFAP cumpriria esse papel promovendo ensino, pesquisa e extensão a assuntos relativos à Ciência da Religião.

Nesse sentido, os/as professores/as que consigam trabalhar as diferentes matrizes religiosas e desenvolvam a necessidade da tolerância religiosa entre os/as alunos/ as, captem as experiências culturais das religiões e religiosidades locais e tragam para o âmbito escolar a formação humanística para os discentes. Portanto a ideia não é reforçar a característica proselitista e dogmática do Ensino Religioso nas escolas defendidas e executadas pela Igreja Católica e segmentos de igrejas evangélicas, e sim promover a diversidade religiosa e o respeito entre elas e demais segmentos da sociedade.

Nas reuniões do grupo de pesquisa Centro de Estudos Políticos, Religião e Sociedade (CEPRES/UNIFAP), é consenso entre os/as docentes-membros que a implantação da graduação em Ciência da Religião por uma instituição pública poderia ajudar professores/as que trabalham com a questão da religião e na formação de novos/as pesquisadores/as, pois constatamos que são raros os estudos sobre religião no Amapá.

Outra motivação foi à vinda do Prof. Dr. Sérgio Rogério Azevedo Junqueira à UNIFAP em 2014 para a participação de banca de defesa de dissertação e eventos ligados ao curso de pós-graduação em Direito Ambiental e Políticas Públicas. Em conversa com esse docente, foi-nos informado que, nos últimos anos, houve a expansão, no Brasil, de curso de graduação e pós-graduação em Ciência da Religião e Teologia, e que isso seria uma tendência em nível nacional; abrir novos cursos de licenciatura e bacharelado no âmbito da Ciência da Religião e a abertura desse curso no estado do Amapá contribuiria para a formação de profissionais qualificados e reduziria o déficit de professores/as dessa área na região Norte.

Com essas motivações, entre outras, iniciamos uma série de reuniões para pensar o Projeto Político-Pedagógico do primeiro Curso de Licenciatura em Ciência da Religião do Amapá e apresentá-lo às instâncias competentes da UNIFAP. Desde o 
início, a Pró-Reitoria de Graduação considerou a ideia interessante e colocou-se à disposição para assessoria na elaboração do projeto.

A partir dessas motivações, idealizamos que os objetivos do curso consistiriam em: (1) formar um profissional consciente de seu papel e importância enquanto cidadão responsável pela educação e pelo desenvolvimento de mentes críticas e criativas; (2) contribuir para a melhoria do ensino e da pesquisa em religião, especificamente na região de abrangência da universidade; (3) formar um professor/pesquisador capaz de inovar e buscar novos caminhos a serem seguidos em sua área de trabalho, respeitando, para isso, os princípios éticos e legais que regem a sua profissão; (4) habilitar profissionais capazes de conhecer as principais vertentes teóricas que orientam as análises da religião e acompanhar os avanços metodológicos das ciências das religiões fazendo implicações no que tange ao Ensino Religioso em prol dos reconhecimentos das diferentes formas religiosas; (5) habilitar o/a acadêmico/a a perceber o espaço escolar como um lócus de pesquisa, na qual a reflexão sobre a sua prática também deve ser constantemente investigada e repensada.

No tocante às habilitações e competências, o/a licenciado/a em Ciência da Religião terá as seguintes capacidades: (a) conhecer as informações básicas referentes às diferentes religiões nas várias tradições civilizatórias, assim como sua inter-relação; (b) transitar pelas fronteiras entre as Ciências da Religião e outras áreas do conhecimento; (c) capacitar para estabelecer relações inter-religiosas coerentes, sequenciais ou simultâneas, entre diferentes culturas, reconhecendo a existência de complexas injunções de novas formas religiosas diante de diferentes ordens culturais, econômicas, políticas e sociais que sustentam e permitem a emergência de tais acontecimentos; (d) conhecer a pluralidade de fundamentos teóricos e metodológicos que sustentam múltiplas facetas da produção religiosa humana, evitando categorizações meramente redutoras e funcionais, buscando devolver aos processos culturais-religiosos sua carga de complexidade e dinamicidade; (e) perceber o papel das ações do sujeito frente às formas religiosas, observando como se dá a relação entre a liberdade de escolha e a determinação da religião; (f) acompanhar e participar do debate das religiões contemporâneas, levando em consideração abordagens e contribuindo para a criação e inclusão de novos objetos de estudo; (g) dominar os conteúdos básicos que são objetos de ensino - aprendizagem no ensino fundamental e médio; (h) dominar os métodos e técnicas pedagógicas que permitem a transmissão do conhecimento para os diferentes níveis de ensino e percepção da aprendizagem como processo de construção de conhecimentos, habilidades e valores em interação com a realidade e com os demais indivíduos.

Além dessas competências e habilidades supracitadas, almejamos que nossos/ as alunos/as possam desempenhar, nas escolas, a função de professores/as-pesquisadores/as com o intuito de, juntamente com os/as alunos/as, elaborar conhecimento sobre Ciência da Religião, lidar com o exercício da tolerância religiosa, saber dialogar com outras áreas do conhecimento, dentre outras competências.

A estrutura curricular da proposta do curso está dividida em quatro eixos: o primeiro eixo denomina-se Ensino Religioso, que consiste nas disciplinas pedagógicas do curso; o segundo eixo, denominamos tradições religiosas, que versa sobre 
as teologias e as narrativas das religiões; o terceiro eixo - linguagens religiosas, que analisa a relação da religião com a sociedade; e, o último eixo, as disciplinas de outras áreas do conhecimento (História, Sociologia, Antropologia, dentre outras), que denominamos de Núcleo Comum das Humanidades, e mais três disciplinas optativas denominadas Tópicos Temáticos.

Quadro 01: Estrutura Curricular

\begin{tabular}{|c|c|c|c|c|}
\hline \multicolumn{5}{|l|}{ Eixo Tradições Religiosas } \\
\hline Componentes Curriculares & $\begin{array}{l}\text { Ch } \\
\text { teórica }\end{array}$ & $\begin{array}{l}\mathrm{Ch} \\
\text { prática }\end{array}$ & $\begin{array}{l}\mathrm{Ch} \\
\text { total }\end{array}$ & Créditos \\
\hline $\begin{array}{l}\text { Textos e Narrativas Sagradas de Matriz Religiosa } \\
\text { Judaica }\end{array}$ & 60 & 0 & 60 & 4 \\
\hline $\begin{array}{l}\text { Textos e Narrativas Sagradas de Matriz Religiosa } \\
\text { Oriental e Africana }\end{array}$ & 60 & 0 & 60 & 4 \\
\hline $\begin{array}{l}\text { Textos e Narrativas Sagradas de Matriz do } \\
\text { cristianismo }\end{array}$ & 60 & 0 & 60 & 4 \\
\hline História das Religiões I & 60 & 0 & 60 & 4 \\
\hline História das Religiões II & 60 & 0 & 60 & 4 \\
\hline Religiões e Religiosidades na Amazônia & 60 & 0 & 60 & 4 \\
\hline Religião e Religiões no Amapá & 60 & 0 & 60 & 4 \\
\hline SUBTOTAL & 420 & 0 & 420 & 28 \\
\hline \multicolumn{5}{|l|}{ Eixo Ensino Religioso - Pedagógicas } \\
\hline Componentes Curriculares & $\begin{array}{l}\mathrm{Ch} \\
\text { teórica }\end{array}$ & $\begin{array}{l}\text { Ch } \\
\text { prática }\end{array}$ & $\begin{array}{l}\mathrm{Ch} \\
\text { total }\end{array}$ & Créditos \\
\hline Filosofia da Educação & 60 & 0 & 60 & 4 \\
\hline Sociologia da Educação & 60 & 0 & 60 & 4 \\
\hline Libras & 75 & 0 & 75 & 5 \\
\hline História do Ensino Religioso no Brasil & 60 & 0 & 60 & 4 \\
\hline Planejamento Educacional & 75 & 0 & 75 & 5 \\
\hline $\begin{array}{l}\text { POLEB - Política e Legislação Educacional } \\
\text { Brasileira }\end{array}$ & 75 & 0 & 75 & 5 \\
\hline Psicologia da Educação & 60 & 0 & 60 & 4 \\
\hline Didática Geral & 75 & 0 & 75 & 5 \\
\hline Educação e Relações Étnico-Raciais & 75 & 0 & 75 & 5 \\
\hline Avaliação Educacional & 75 & 0 & 75 & 5 \\
\hline Prática de Ensino I & 30 & 75 & 105 & 7 \\
\hline Prática de Ensino II & 30 & 75 & 105 & 7 \\
\hline Estágio Supervisionado em Docência I & 30 & 180 & 210 & 14 \\
\hline Estágio Supervisionado em Docência II & 30 & 180 & 210 & 14 \\
\hline Educação Inclusiva & 75 & 0 & 75 & 5 \\
\hline SUBTOTAL & 831 & 510 & 1341 & 93 \\
\hline
\end{tabular}




\begin{tabular}{|c|c|c|c|c|}
\hline \multicolumn{5}{|l|}{ Eixo Linguagens Religiosas } \\
\hline Componentes Curriculares & $\begin{array}{l}\mathrm{Ch} \\
\text { teórica }\end{array}$ & $\begin{array}{l}\text { Ch } \\
\text { prática }\end{array}$ & $\begin{array}{l}\mathrm{Ch} \\
\text { total }\end{array}$ & Créditos \\
\hline Antropologia da Religião & 60 & 0 & 60 & 4 \\
\hline Filosofia da Religião & 60 & 0 & 60 & 4 \\
\hline Sociologia da Religião & 60 & 0 & 60 & 4 \\
\hline Psicologia da Religião & 60 & 0 & 60 & 4 \\
\hline Religião e Linguagem & 60 & 0 & 60 & 4 \\
\hline Religião e Política & 60 & 0 & 60 & 4 \\
\hline Diálogo Inter-Religioso & 60 & 0 & 60 & 4 \\
\hline Religião e Direitos Humanos & 60 & 0 & 60 & 4 \\
\hline Religião e Gênero & 60 & 0 & 60 & 4 \\
\hline Geografia da Religião & 60 & 0 & 60 & 4 \\
\hline SUBTOTAL & 600 & 0 & 600 & 40 \\
\hline \multicolumn{5}{|l|}{ Núcleo Comum das Humanidades } \\
\hline Componentes Curriculares & $\begin{array}{l}\text { Ch } \\
\text { teórica }\end{array}$ & $\begin{array}{l}\text { Ch } \\
\text { prática }\end{array}$ & \begin{tabular}{|l}
$\mathrm{Ch}$ \\
total
\end{tabular} & Créditos \\
\hline Leitura e Produção de Texto & 60 & 0 & 60 & 4 \\
\hline TCC 1 & 40 & 20 & 60 & 4 \\
\hline TCC 2 & 00 & 60 & 60 & 4 \\
\hline Introdução à Filosofia & 60 & 0 & 60 & 4 \\
\hline Introdução à Sociologia & 60 & 0 & 60 & 4 \\
\hline Antropologia Cultural & 60 & 0 & 60 & 4 \\
\hline Metodologia Científica & 60 & 0 & 60 & 4 \\
\hline História Econômica e Política do Brasil & 60 & 0 & 60 & 4 \\
\hline SUBTOTAL & 400 & 80 & 480 & 24 \\
\hline \multicolumn{5}{|l|}{ Curso de Licenciatura em Ciência da Religião } \\
\hline Componentes Curriculares & \begin{tabular}{|l|} 
Ch \\
teórica
\end{tabular} & $\begin{array}{l}\text { Ch } \\
\text { prática }\end{array}$ & \begin{tabular}{|l} 
Ch \\
total
\end{tabular} & Créditos \\
\hline Eixo Ensino Religioso - Pedagógicas & 831 & 510 & 1341 & 93 \\
\hline Eixo Tradições Religiosas & 420 & 0 & 420 & 28 \\
\hline Eixo Linguagens Religiosas & 600 & 0 & 600 & 40 \\
\hline Eixo Núcleo Comum de Humanidades & 400 & 80 & 480 & 24 \\
\hline Optativa & 180 & 0 & 180 & 12 \\
\hline Atividades Acadêmico-Científico-Culturais & 210 & 0 & 210 & 14 \\
\hline SUBTOTAL & 2641 & 590 & 3231 & 211 \\
\hline TOTAL & \multicolumn{4}{|c|}{3231} \\
\hline
\end{tabular}

Fonte: UNIFAP, 2016. 
A partir dessa estrutura curricular, pensamos o Estágio Supervisionado como forma de desenvolver em nossos/as alunos/as princípios que norteiam o processo de ensino em Ciência da Religião. As disciplinas de Estágio Supervisionado I e II (voltado para o ensino fundamental I e II), coordenadas pelos/as professores/as do curso de Ciência da Religião e Seminário de Prática de Ensino I e II. Os/as alunos/as poderão fazer estágios em escolas públicas e privadas.

Quadro 02: Matriz Curricular - Licenciatura em Ciência da Religião

\begin{tabular}{|c|c|c|c|c|c|}
\hline \multicolumn{6}{|l|}{$1^{\circ}$ Semestre } \\
\hline Componentes Curriculares & $\begin{array}{l}\mathrm{Ch} \\
\text { teórica }\end{array}$ & $\begin{array}{l}\text { Ch } \\
\text { prática }\end{array}$ & $\begin{array}{l}\mathrm{Ch} \\
\text { total }\end{array}$ & Créditos & $\begin{array}{l}\text { Pré- } \\
\text { requisito }\end{array}$ \\
\hline Leitura e Produção de Texto & 60 & 0 & 60 & 4 & - \\
\hline Introdução à Ciência da Religião & 60 & 0 & 60 & 4 & - \\
\hline Introdução à Filosofia & 60 & 0 & 60 & 4 & - \\
\hline Introdução à Sociologia & 60 & 0 & 60 & 4 & - \\
\hline Antropologia Cultural & 60 & 0 & 60 & 4 & - \\
\hline $\begin{array}{l}\text { História Econômica e Política do } \\
\text { Brasil }\end{array}$ & 60 & 0 & 60 & 4 & - \\
\hline Total & 360 & 0 & 360 & 24 & - \\
\hline \multicolumn{6}{|l|}{$2^{\circ}$ Semestre } \\
\hline Componentes Curriculares & $\begin{array}{l}\mathrm{Ch} \\
\text { teórica }\end{array}$ & $\begin{array}{l}\text { Ch } \\
\text { prática }\end{array}$ & $\begin{array}{l}\mathrm{Ch} \\
\text { total }\end{array}$ & Créditos & Requisito \\
\hline Metodologia Científica & 60 & 0 & 60 & 4 & - \\
\hline Antropologia da Religião & 60 & 0 & 60 & 4 & - \\
\hline Psicologia da Religião & 60 & 0 & 60 & 4 & - \\
\hline Sociologia da Religião & 60 & 0 & 60 & 4 & - \\
\hline Filosofia da Religião & 60 & 0 & 60 & 4 & - \\
\hline $\begin{array}{l}\text { Textos e Narrativas Sagradas de } \\
\text { Matriz Religiosa Judaica }\end{array}$ & 60 & 0 & 60 & 4 & - \\
\hline Total & 360 & 0 & 360 & 24 & - \\
\hline \multicolumn{6}{|l|}{$3^{\circ}$ Semestre } \\
\hline Componentes Curriculares & $\begin{array}{l}\mathrm{Ch} \\
\text { teórica }\end{array}$ & $\begin{array}{l}\text { Ch } \\
\text { prática }\end{array}$ & $\begin{array}{l}\mathrm{Ch} \\
\text { total }\end{array}$ & Créditos & Requisito \\
\hline Filosofia da Educação & 60 & 0 & 60 & 4 & \\
\hline Didática Geral & 75 & 0 & 60 & 5 & - \\
\hline História das Religiões I & 60 & 0 & 60 & 4 & - \\
\hline $\begin{array}{l}\text { Textos e Narrativas Sagradas de } \\
\text { Matriz Religiosa Oriental e Africana }\end{array}$ & 60 & 0 & 60 & 4 & - \\
\hline Linguagem e Religião & 60 & 0 & 60 & 4 & - \\
\hline LIBRAS & 75 & 0 & 75 & 5 & - \\
\hline Total & 390 & 0 & 375 & 26 & \\
\hline
\end{tabular}




\begin{tabular}{|c|c|c|c|c|c|}
\hline \multicolumn{6}{|l|}{$4^{\circ}$ Semestre } \\
\hline Componentes Curriculares & $\begin{array}{l}\text { Ch } \\
\text { teórica }\end{array}$ & $\begin{array}{l}\text { Ch } \\
\text { prática }\end{array}$ & $\begin{array}{l}\mathrm{Ch} \\
\text { total }\end{array}$ & Créditos & Requisito \\
\hline Planejamento Educacional & 75 & 0 & 75 & 5 & - \\
\hline $\begin{array}{l}\text { PROLEB - Política e Legislação } \\
\text { Educacional Brasileira }\end{array}$ & 75 & 0 & 75 & 5 & - \\
\hline História do Ensino Religioso no Brasil & 60 & 0 & 60 & 4 & - \\
\hline $\begin{array}{l}\text { Textos e Narrativas Sagradas de } \\
\text { Matriz do Cristianismo }\end{array}$ & 60 & 0 & 60 & 4 & - \\
\hline História das Religiões II & 60 & 0 & 60 & 4 & \\
\hline Geografia da Religião & 60 & 0 & 60 & 4 & - \\
\hline Total & 390 & 0 & 390 & 26 & - \\
\hline \multicolumn{6}{|l|}{$5^{\circ}$ Semestre } \\
\hline Componentes Curriculares & $\begin{array}{l}\mathrm{Ch} \\
\text { teórica }\end{array}$ & $\begin{array}{l}\text { Ch } \\
\text { prática }\end{array}$ & $\begin{array}{l}\mathrm{Ch} \\
\text { total }\end{array}$ & Créditos & Requisito \\
\hline Educação e Relações Etnorraciais & 75 & 0 & 75 & 5 & - \\
\hline Psicologia da Educação & 60 & 0 & 60 & 4 & - \\
\hline Prática de Ensino I & 30 & 75 & 105 & 7 & - \\
\hline Tópicos Temáticos I & 60 & 0 & 60 & 4 & - \\
\hline Religião e Direitos Humanos & 60 & 0 & 60 & 4 & \\
\hline $\begin{array}{llll}\text { Religiões } & \text { e } & \text { Religiosidades } & \text { da } \\
\text { Amazônia }\end{array}$ & 60 & 0 & 60 & 4 & - \\
\hline Total & 345 & 75 & 420 & 28 & - \\
\hline \multicolumn{6}{|l|}{$6^{\circ}$ Semestre } \\
\hline Componentes Curriculares & $\begin{array}{l}\text { Ch } \\
\text { teórica }\end{array}$ & $\begin{array}{l}\text { Ch } \\
\text { prática }\end{array}$ & $\begin{array}{l}\text { Ch } \\
\text { total }\end{array}$ & & Requisito \\
\hline Prática de Ensino II & 30 & 75 & 105 & 7 & - \\
\hline Tópicos Temáticos II & 60 & 0 & 60 & 4 & \\
\hline Sociologia da Educação & 60 & 0 & 60 & 4 & - \\
\hline Avaliação Educacional & 75 & 0 & 75 & 5 & - \\
\hline Religião e Gênero & 60 & 0 & 60 & 4 & - \\
\hline Religião e Religiões do Amapá & 60 & 0 & 60 & 4 & - \\
\hline Total & 345 & 75 & 420 & 28 & - \\
\hline \multicolumn{6}{|l|}{$7^{\circ}$ Semestre } \\
\hline Componentes Curriculares & $\begin{array}{l}\text { Ch } \\
\text { teórica }\end{array}$ & $\begin{array}{l}\text { Ch } \\
\text { prática }\end{array}$ & $\begin{array}{l}\mathrm{Ch} \\
\text { total }\end{array}$ & Créditos & Requisito \\
\hline Tópicos Temáticos III & 60 & 0 & 60 & 4 & - \\
\hline Religião e Política & 60 & 0 & 60 & 4 & - \\
\hline
\end{tabular}




\begin{tabular}{|c|c|c|c|c|c|}
\hline Educação Inclusiva & 75 & 0 & 75 & 5 & - \\
\hline Dialogo Inter-Religioso & 60 & 00 & 60 & 4 & \\
\hline TCC I & 40 & 20 & 60 & 4 & - \\
\hline Estágio Supervisionado em Docência I & 30 & 180 & 210 & 14 & - \\
\hline Total & 325 & 200 & 525 & 35 & \\
\hline \multicolumn{6}{|l|}{$8^{\circ}$ Semestre } \\
\hline Componentes Curriculares & $\begin{array}{l}\text { Ch } \\
\text { teórica }\end{array}$ & $\begin{array}{l}\text { Ch } \\
\text { prática }\end{array}$ & $\begin{array}{l}\mathrm{Ch} \\
\text { total }\end{array}$ & Créditos & Requisito \\
\hline $\begin{array}{l}\text { Estágio Supervisionado em Docência } \\
\text { II }\end{array}$ & 30 & 180 & 210 & 14 & \\
\hline $\begin{array}{l}\text { Atividades Acadêmico-Científico- } \\
\text {-Culturais }\end{array}$ & 00 & 210 & 210 & 14 & - \\
\hline TCC II & 00 & 60 & 60 & 4 & - \\
\hline Total & 30 & 450 & 480 & 30 & \\
\hline RESUMO DA CARGA HORÁRIA & \multicolumn{5}{|c|}{3.231} \\
\hline Carga Horária Total (H/A) & \multicolumn{5}{|c|}{3.231} \\
\hline
\end{tabular}

Fonte: UNIFAP, 2016.

$\mathrm{O}$ perfil dos/as docentes escolhidos/as foi de profissionais que desenvolvem atividades vinculadas à pesquisa, ao ensino e à extensão na área de Ciência da Religião, mestres e doutores que estão interessados na produção do conhecimento sobre religião e religiosidade no estado do Amapá. A ideia é que sejam contratados/as outros/as professores/as (preferencialmente doutores/as) que se encaixem nesse perfil acadêmico.

$\mathrm{Na}$ atualidade, o único grupo de pesquisa que tem por foco o estudo sistemático da religião e religiosidade no estado do Amapá é o CEPRES/UNIFAP. Fazemos reunião, quinzenalmente, nas dependências da UNIFAP para discutir textos relativos à área de Ciência da Religião. Os/as docentes vinculados/as, entre pesquisadores/as de outras instituições, desenvolvem pesquisas nas temáticas relacionadas à religião e à política, mídia e religião, religião e educação, direitos humanos, religião e relações internacionais, dentre outras temáticas.

Um dos projetos em andamento desenvolvido pelo grupo é a participação político-partidária dos católicos carismáticos no estado do Amapá, desenvolvido pelo Prof. Dr. Marcos Vinicius de Freitas Reis, seguindo-se da pesquisa do Prof. Dr. Andrius Estevam Noronha sobre o perfil do clero católico e de alguns segmentos evangélicos. Há alguns anos, o Prof. Msc. Elivaldo Serrão Custódio vem desenvolvendo estudos sobre a formação de professores/as de Ensino Religioso escolar no Amapá, bem como atualmente sua pesquisa de doutorado sobre religião e relações étnico-raciais na educação pública em áreas quilombolas. O Prof. Msc. Antônio de Almeida Rodrigues da Silva tem-se dedicado aos estudos relativos à filosofia da religião e o Prof. Msc. Renan Marques Birro sobre as questões religiosas na Idade Média, dentre outros projetos. 
Pretendemos, em médio prazo, desenvolver projetos de extensão, a exemplo da promoção de exibição de filmes sobre religião para a comunidade acadêmica e escolas públicas e privadas, bem como oferta de cursos de formação continuada para professores/as da rede pública de ensino, dentre outras iniciativas. À medida que o nosso corpo docente for aumentando a titulação e a publicação, pretendemos criar uma linha de pesquisa sobre o estudo da Ciência da Religião em algum programa de pós-graduação da UNIFAP e, a médio prazo, pensar na proposta de elaboração de uma especialização e mestrado em Ciência da Religião.

No ano de 2016, a coordenação geral do Plano Nacional de Formação de Professores/as (PARFOR) da UNIFAP solicitou ao grupo de pesquisadores/as do CEPRES uma reunião para discutir a possibilidade da criação do Curso de Licenciatura em Ciência da Religião nessa modalidade. A iniciativa deu-se em virtude da significativa procura pelo curso e o fato da maioria dos/as docentes que atuam com o componente curricular Ensino Religioso nas escolas públicas do estado do Amapá não ter formação na área para trabalhar esses conteúdos.

Na reunião, fomos informados que existe a expectativa da primeira turma ser aberta em 2017 e que haveria comprometimento dos meios de comunicação local para ampla divulgação do curso, e que a SEED permitiria que os/as professores/as fossem liberados/as para participar das aulas. Sendo assim, foi aberta a comissão de criação do Projeto Pedagógico Curricular (PPC) do Curso de Licenciatura em Ciência da Religião e o seu respectivo Núcleo Docente Estruturante (NDE), como mostra os quadros 3 e 4 a seguir:

Quadro 3: Comissão para elaboração do PPC do Curso de Licenciatura em Ciência da Religião no Amapá

\begin{tabular}{|c|c|c|}
\hline Nome completo & Titulação & Colegiado e/ou Instituição \\
\hline Afrânio Patrocínio Andrade & Doutor & Filosofia \\
\hline Aldenor Benjamim dos Santos & Doutor & Jornalismo \\
\hline Andrius Estevam Noronha & Doutor & História \\
\hline Antônio Almeida Rodrigues da Silva & Mestre & Filosofia \\
\hline Boaz Andrade Barros & Especialista & $\begin{array}{c}\text { Acadêmico do Curso de } \\
\text { Letras UNIFAP }\end{array}$ \\
\hline Elivaldo Serrão Custódio & Mestre & Professor da SEED \\
\hline Fábio Py Murta de Almeida & Doutor & PUC RJ \\
\hline José Carlos Cariacás Romão dos Santos & Doutor & Filosofia \\
\hline Maria de Lurdes Sanches Vulcão & Mestre & Professora SEED \\
\hline Marcos Vinícius de Freitas Reis & Doutor & Relações Internacionais \\
\hline Paulo Roberto Moraes de Mendonça & Mestre & Filosofia \\
\hline Rafael Cesar Pitt & Mestre & Filosofia \\
\hline Renan Marques Birro & Mestre & $\begin{array}{c}\text { História (Campus } \\
\text { Binacional-AP) }\end{array}$ \\
\hline Roberto José Nery Moraes & Mestre & Direito \\
\hline
\end{tabular}


Quadro 4: Comissão do NDE do Curso de Licenciatura em Ciência da Religião

\begin{tabular}{|c|c|c|}
\hline Nome completo & Titulação & Colegiado \\
\hline Afrânio Patrocínio Andrade & Doutor & Filosofia \\
\hline Andrius Estevam Noronha & Doutor & História \\
\hline Antônio Almeida Rodrigues da Silva & Mestre & Filosofia \\
\hline José Carlos Cariacás Romão dos Santos & Doutor & Filosofia \\
\hline Marcos Vinícius de Freitas Reis & Doutor & Relações Internacionais \\
\hline
\end{tabular}

Em linhas gerais, apresentamos as motivações que nos levaram a criar a proposta da implementação do primeiro Curso de Licenciatura de Ciência da Religião nas dependências da UNIFAP no estado do Amapá, assim como também as principais competências, habilidades, perfil e a organização curricular. Ressaltamos que o referido projeto de criação do Curso de Licenciatura de Ciência da Religião está em análise e que estamos em processo de elaboração do Projeto Político Pedagógico (PPP) e acreditamos que, nos próximos meses, apresentaremos, à UNIFAP e sociedade em geral, a primeira versão do projeto.

\section{Considerações finais}

A pesquisa constatou que, nos últimos anos, não houve por parte dos sistemas de ensino estadual do Amapá um plano de políticas educacionais e/ou ações para formação e/ou capacitação de professores/as de Ensino Religioso. Não há registros de políticas educacionais nessa área.

A pesquisa constatou ainda que o estado do Amapá ainda não encontrou um caminho para responder ao desafio da formação de professores/as de Ensino Religioso. Isso requer um caminho que, independente de partidos políticos, o estado e outras instituições de ensino superior devem oferecer curso de Licenciatura Plena - habilitação em Ensino Religioso para qualificação de professores/as e que esse componente curricular possa continuar fazendo parte do currículo normal das disciplinas curriculares da área do conhecimento das escolas públicas.

Somos conhecedores de que cada estado, dentro de sua realidade, tem suas particularidades, suas limitações, entretanto, acreditamos que cada estado também necessita incluir nas políticas de formação os/as professores/as de Ensino Religioso, possibilitando-lhes o acesso à licenciatura plena com habilitação na disciplina.

O estudo traz uma importante contribuição social no sentido de levar questões pertinentes à urgente necessidade de formação de professores/as de Ensino Religioso; de oferecer subsídios para reflexão e a possível definição de políticas para a continuidade da formação de docentes no estado do Amapá. A pesquisa não pretendeu esgotar a temática, e sim levantar questões para possíveis aprofundamentos, reflexões e novas pesquisas.

O presente trabalho abordou a realidade da formação dos/as docentes de Ensino Religioso e seu histórico, motivações e o perfil da proposta do curso de graduação 
de licenciatura em Ciência da Religião idealizado por um grupo de pesquisadores/as e docentes da UNIFAP.

No decorrer da elaboração da proposta, temos encontrado algumas dificuldades. Uma delas é a própria resistência de setores da UNIFAP à adesão da criação do curso, pois entendem que existem outras prioridades de criação de cursos de graduação, a exemplo do curso de Psicologia, e ainda argumentam que a universidade já possui muitos cursos de licenciatura e precisa investir em áreas de bacharelado.

Outra dificuldade do grupo é que alguns e algumas docentes e técnicos/as que, atualmente, compõem a Câmara de Ensino e o Conselho Universitário (CONSU) são contrários à criação de qualquer outro curso na universidade por entenderem que a instituição precisa consolidar os cursos existentes e que não há espaço físico para a criação de novos cursos.

E, por fim, a própria burocracia da universidade é muito lenta. Demoram-se semanas para que o projeto possa tramitar nos órgãos competentes. Percebemos isso pela experiência de propostas de outros cursos. Independente dessas dificuldades, acreditamos que a formação de professores/as e pesquisadores/as na área da Ciência da Religião no estado do Amapá é urgente.

Precisamos de profissionais que consigam desenvolver pesquisas para entendermos a dinâmica da religião no estado e que esses possam desenvolver suas práticas da sala de aula com capacitação no Ensino Religioso. Com esses objetivos, a comissão continua se reunindo, esporadicamente, aprimorando o projeto e articulando com lideranças da UNIFAP para aprovação do curso.

\section{Referências}

BRASIL. Constituição da República Federativa do Brasil de 1988. Brasília. Disponível em: $<$ http://www.senado.gov.br/sf/legislacao/const/con1988/CON1988_30.06.2004/CON1988.pdf>. Acesso em: 20 jul. 2014.

. Lei $n^{\circ}$ 9.394/1996. Lei de Diretrizes e Bases da Educação Nacional. Brasília, 1996. Disponível em <http://www.planalto.gov.br/ccivil_03/Leis/L9394.htm>. Acesso em: 20 jul. 2014. . Lei $n^{\circ}$ 9.475/1997. Lei de Diretrizes e Bases da Educação Nacional. Brasília, 1997. Disponível em: <http:// www.edutec.net/Leis/Educacionais/ed19475.htm>. Acesso em: 20 jul. 2014. . Resolução $n^{\circ}$ 14/2006. Conselho Estadual de Educação/AP. Macapá, 12 de fevereiro de 2006. Disponível em: <www.gper.com.br/biblioteca_download.php?arquivoId=136>. Acesso em: 20 jul. 2014.

. Ministério da Educação. Instituições de Educação Superior e Cursos Cadastrados em 2016. Disponível em: <http://emec.mec.gov.br/>. Acesso em: 02 jul. 2016.

CARON, Lurdes. Políticas e Práticas Curriculares: Formação de professores de Ensino Religioso. 2007. Tese (Doutorado em Educação: currículo) - Pontifícia Universidade Católica de São Paulo - PUC-SP, São Paulo, 2007. 354p. Disponível em: <http://www.sapientia.pucsp.br/ tde_arquivos/11/TDE-2008-01-03 T06:54:24Z-4689/Publico/Lurdes\%20Caron\%20desp\%20 (sem\%20o\%20anexo\%203).pdf>. Acesso em: 08 jun. 2014.

. Entre Conquistas e Concessões: uma experiência ecumênica em educação religiosa escolar. São Leopoldo: Sinodal, 1997. 
CARON, Lurdes. Políticas públicas para a formação de professores para a educação básica. In: JUNQUEIRA, Sérgio Rogério Azevedo; OLIVEIRA, Lílian Blanck (Orgs.). Ensino Religioso: memórias e perspectivas. Curitiba: Champagnat, 2005. p. 99-117.

. Experiências e propostas de educação continuada. I Fórum de Ensino Religioso. Secretaria de Educação e Cultura e Faculdade Católica de Tocantins, 2005. p. 19-20.

CUSTÓDIO, Elivaldo Serrão. Formação de professores de ensino religioso no Amapá. In: SEMINÁRIO NACIONAL DE FORMAÇÃO DE PROFESSORES PARA O ENSINO RELIGIOSO, 12., 2012, Manaus. Anais... Florianópolis: Fonaper, 2012. p. 420-429. Disponível em: <www. gper.com.br/biblioteca_download.php?arquivold=880>. Acesso em: 20 jul. 2014.

Políticas públicas e direito ambiental cultural: as religiões de matrizes africanas no currículo escolar no Amapá, 2014. 198f. Dissertação (Mestrado em Direito Ambiental e Políticas Públicas) - Universidade Federal do Amapá, Macapá, 2014.

FACULDADE DE TEOLOGIA E CIÊNCIAS HUMANAS (FATECH/AP). Disponível em: $<$ http://faculdadefatech.com.br>. Acesso em: 25 ago. 2015.

JUNQUEIRA, Sérgio Rogério Azevedo. O processo de escolarização do Ensino religioso no Brasil. Petrópolis: Vozes, 2002.

JUNQUEIRA, Sergio et al. Formação do professor de ensino religioso: uma realidade desafiadora no Brasil. 2006. Disponível em: $<$ http://www.pucpr.br/eventos/educere/educere2006/anaisEvento/ docs/CI-041-TC.pdf>. Acesso em: 10 jun. 2014.

NÓVOA, Antonio. Os professores e a sua formação. Lisboa: Dom Quixote, 1992.

REIS, Marcos Vinicius de Freitas; CARMO, Arielson Teixeira do. O campo religioso amapaense: Uma análise a partir do Censo do IBGE de 2000 e 2010. Observatório da Religião, Belém-PA, v. 2, n. 2, p. 175-197, jun./dez. 2015. Disponível em: <http://paginas.uepa.br/seer/index.php/ Religiao/article/view/834/595>. Acesso em: 04 jun. 2016.

SOUZA, André Ricardo. Pluralismo Cristão Brasileiro. Caminhos, Goiânia, v. 10, n. 1, p. 129-141, jan./jun. 2012. Disponível em: <http://seer.ucg.br/index.php/caminhos/article/view/1953/1218>. Acesso em: 05 jan. 2016. 